\title{
Nafsiyat: a psychotherapy centre for ethnic minorities
}

\author{
SOURANGSHU ACHARYYA, Research Director; SHARON MOORHOUSE, Research \\ Psychologist; JAFAR KaREem, Clinical Director; Roland LITTLEWOOD, Chairman of \\ Research Committee; Nafsiyat Inter-Cultural Therapy Centre, Islington, London N4
}

Nafsiyat, a community based 'intercultural therapy centre', was set up in London in 1983 to provide psychotherapy for people from ethnic and cultural minority backgrounds.

A variety of community mental health facilities have now been established in Britain (Peet, 1986). While there is evidence that the population utilising them has a different clinical and social profile from that found in hospital based facilities (Hutton, 1985), this has to be balanced against the current trend of an overall reduction in hospital facilities, with community services taking over the treatment of some people previously seen in psychiatric hospitals. Together with these changes, there is now recognised to be concern about appropriate mental health provision (whether community based or otherwise) for ethnic minorities. While the availability of psychotherapy for all groups is less than the demand, this is particularly true for black and minority groups. It appears that professionals are ambivalent about their ability to provide psychotherapy for minorities: Littlewood \& Lipsedge (1982) suggest that such patients are traditionally excluded from psychotherapy, while black patients appear more likely to be offered medication rather than psychotherapy or counselling, a finding which is independent of diagnosis (Littlewood \& Cross, 1980).

This situation needs to be seen in the context of a society in which 3.4 million people were born overseas; 1.41 million were born in the New Commonwealth and Pakistan; 153,000 in the Old Commonwealth; 607,000 in Ireland and 1.13 million born in other countries including Western Europe. Of Britain's 2.2 million people with ethnic origins in the New Commonwealth and Pakistan, over $40 \%$ were born in Britain; and of these $56 \%$ live within Greater London and the South East (Commission for Racial Equality, 1985). Minority groups experience deprivation in many areas: housing, education, employment and health care, as well as the experience of overt and covert racism in daily life. For the migrant generation there is also the stress of adjustment. Such continuing experiences are likely to have psychological effects on personal identity, and on successful personal adjustment.

While the failure to provide psychotherapy may, in part, be due to institutional racism, there is still the practical difficulty of offering psychotherapy to patients whose background and cultural identity may differ from those of the therapist: different life experiences, dominant cultural idiom, moral concepts and prejudices, and frequently a difference in first language between the therapist and the patient. Modes of expression of distress as well as their personal meaning may differ between patient and therapist (Kareem, 1978).

\section{Development of Nafsiyat}

In the 1970s a group of professionals in London, who were working in the health and social services with clients from a diverse range of backgrounds and origins, recognised the need for a new psychotherapy facility. Some of them were themselves from minority backgrounds and found that they were asked to act as interpreters of language and culture, including cultural metaphors and expressions of illness (typically 'somatic expression' of psycho-social problems). They decided to develop a psychotherapy service that not only had an understanding of racism and cultural issues, but also could provide advice, support and training for others working in primary health care, the social services and psychiatry.

The centre, Nafsiyat, was envisaged as having three main functions:

(a) psychotherapy with adults, adolescents and children

(b) training

(c) case consultation with other professions.

The therapy was to be primarily a form of dynamic psychotherapy described by the clinical doctor as a psychotherapy "that takes into account the whole being of the patient - not only the individual concepts and constructs as presented to the therapist, but also the patient's communal life experiences in the world - both past and present. The very fact of being from another culture employs both conscious and unconscious assumptions - both in the patient and in the therapist; and we believe that for successful outcome of therapy, addressing these conscious and unconscious assumptions is essential" (Kareem, 1987). While this remains the theoretical basis for the service offered, certain modifications have been introduced with the developing structure of the 
organisation and its funding. What is currently offered to patients is brief, focused, dynamic psychotherapy for- 12 sessions. In certain cases, the number of sessions can be extended, typically up to 20 sessions. Understanding the 'culture' of patients includes taking into account both their personal experiences in the societies in which they were born and lived, the experience of the 'migrant culture' of parents and grandparents, and the way of life created by minorities in British society to affirm and maintain their own identity, a way of life into which subsequent generations are born.

\section{Organisation}

Nafsiyat is jointly funded by Islington Borough Council and Islington District Health Authority. From October 1985 the Department of Health and Social Security has funded a three year research programme to evaluate the Centre. Established in 1983, it moved the next year into the current premises in Finsbury Park, North London - an area with a large population of black and ethnic minority residents (Commission for Racial Equality, 1985). The Centre occupies the first and second floors of a house in the high street of Seven Sisters Road, close to Finsbury Park Underground station. Accommodation includes a general office, waiting room, the clinical director's office, two sessional workers' rooms, a research office, kitchen and wash rooms. The limited accommodation primarily determines the number of people that are seen.

Nafsiyat is staffed by therapists who are themselves from diverse cultural backgrounds. The clinical director, the originator of the concept, and the only directly funded member of staff, is an analytical psychotherapist. He has worked in the intercultural field in Austria, Israel and elsewhere in England. Other staff include analytically trained psychotherapists and psychiatrists, and counsellors with backgrounds in social work or clinical psychology. A child psychotherapist works predominantly with child and adolescent cases. Two psychiatrists provide psychiatric backup, assessment and advice, and a research psychologist sponsored by the DHSS is evaluating the service. There is provision for one full-time administrator/secretary who provides administrative backup for the Centre and for a parttime secretary. Two members of staff are registered for postgraduate degrees with the Department of Psychiatry at University College, London University, with whom close academic and clinical links are maintained.

\section{Patients}

Six hundred and twenty patients have been referred to Nafsiyat since 1983, the majority in their late teens and twenties, with more women than men referred (sex ratio 1.5:1). While patients usually come by way of one of the statutory services, $23 \%$ are self referred. A partial retrospective analysis suggests that the Centre is not treating the 'worried well' but a population who have profound psychiatric distress. Of 54 random cases, $13 \%$ were referred with a diagnosis of schizophrenia, paranoid disorder or major affective disorder. When the patients were given a diagnosis at the Centre using DSM-III, the number of patients in these categories was $20 \%$. Thirty-eight per cent of patients had previously seen more than one psychiatric or other medical specialist, with one patient having seen 12 professionals. A provisional analysis of the outcome of therapy supports the contention that psychotherapy for ethnic minorities is a useful therapeutic intervention. Over two-thirds of the patients reported improvement in several areas of their lives, for example in inter-personal relationships or in coping with their problems more effectively. Although these results are based on a small retrospective sample, current analysis of the prospective research is producing similar results. This examines the socio-demographic attributes of the population (sex, marital status, employment, country of birth, ethnicity, and personal choice of ethnicity), together with diagnostic issues - the differences in interpretation of the distress by the professional and the patient - to determine how this might lead to misunderstanding and consequent problems with diagnosis and treatment.

Continuous monitoring of its own efficacy has always been a consideration at Nafsiyat. Papers are currently being prepared for publication examining such areas as the population profile, diagnosis and the effectiveness of the service.

Patients are not ethnically or culturally matched with their therapist, unless there are language constraints. The term 'intercultural' was chosen deliberately to demonstrate that a professional from one cultural or racial background could work effectively with a patient from another. A retrospective survey of $\mathbf{4 7 2}$ patients on whom there was adequate information as to the exact place of birth showed that $32 \%$ were born in South Asia, 13\% in the West Indies, $17 \%$ in Africa, and 9\% were born in Europe. Twenty-one per cent of the patients were not immigrants but first, and in some cases second, generation British-born. This is an important finding, given that most of the research and policy in transcultural psychiatry still assumes that members of ethnic and cultural minorities are 'immigrants' (which itself raises a number of questions as to why British-born people should request 'inter-cultural' therapy).

\section{Procedure}

The initial referral is discussed at the weekly clinical meeting of the clinical and research directors, the 
child psychotherapist, the psychologist and the secretary, and any sessional workers who are able to attend. This meeting decides whether the patient is suitable for the type of therapy that Nafsiyat offers and should be invited for an assessment interview, or whether the professional currently working with the patient should be offered supervision from the Centre.

At the subsequent assessment interview, the clinical director completes a case history form, a psychiatric symptom checklist and the patient completes the General Health Questionnaire. Patients are given information about the service and they then decide if they wish to continue. If they do then they are seen by a psychiatrist who administers the Present State Examination. It is considered imperative to reinforce purely psychotherapeutic interventions with objective measures of psychiatric symptomatology. Patients are then allocated a therapist who offers 1250 -minute sessions, usually on a weekly basis. At the end of this contract the situation is jointly reassessed and further time is offered if appropriate, negotiated in the form of a new contract for a specified number of sessions. All patients living in the borough of Islington receive therapy free of charge. Other patients are funded through their local authorities, DHAs or other agencies. In a few cases patients pay for their therapy themselves.

\section{Teaching}

The Nafsiyat team initially hoped that such a centre would eventually become redundant through the increasing sensitivity and awareness of professionals. It was never intended that Nafsiyat would itself generate other groups countrywide, but rather that it would teach people from different backgrounds to work cross-culturally (or, in Nafsiyat's term, 'interculturally'). To this end much time and effort has been invested in training other professionals, generally in the form of seminars and workshops. Courses taught include a multidisciplinary course organised in conjunction with the Department of General Practice at St Bartholomew's Hospital Medical School; an Islington Residential Social Workers Course; a Nafsiyat Mental Health Training Conference (1987) and the joint Nafsiyat/University College/Tavistock Clinic seminars (1988).
Nafsiyat workers regard as a major area of future development the provision of practical and theoretical training courses to give other professionals skills, insight and understanding in their work with clients of different cultural backgrounds. To this end a proposal for a joint postgraduate diploma in inter-cultural therapy is being prepared with the Department of Psychiatry, University College, London.

\section{Concluding remarks}

Nafsiyat challenges many of the preconceptions which have been traditionally associated with 'psychotherapy' and 'trans-cultural psychiatry': that ethnic and cultural minorities are unsuitable for therapy; that payment is necessary for successful therapy; that it always requires long-term commitment with frequent attendance. It also requires workers in this area radically to re-examine their own definition of cultural and racial issues as well as their personal way of working.

A major issue is the importance of personal and shared culture in the development of mental distress and the significance of this in the therapeutic process. Nafsiyat's training of professionals emphasises the dynamic role of culture and our need to develop communication skills to work effectively with clients with backgrounds different from our own.

\section{References}

Commassion por RACLAL EQUaltry (1985) Ethnic Minorities in Britain: Statistical Information on the Pattern of Settlement. London: CRE.

Hutron, F. (1985) Self-referrals to a community mental health centre: A three year study. British Journal of Psychiatry, 147, 540-544.

KAREEM, J. (1978) Conflicting concepts of mental health in a multi-cultural society. Psychiatrica Clinica, 11, 90-95.

- (1987) Clinical Director's Address. Nafsiyat Training Conference 1987, Eastbourne.

LirturwOOD, R. \& Cross, S. (1980) Ethnic minorities and psychiatric services. Sociology of Health and Illness, 2, 194-201.

— LIPSEDGE, M. (1982) Aliens and Alienists; Ethnic Minorities and Psychiatry. Harmondsworth: Penguin.

PEET, M. (1986) Network community mental health care in North West Derbyshire. Bulletin of the Royal College of Psychiatrists, 10, 262-265. 